\title{
Heuristic Evaluation of the use of Blackboard \& Facebook Groups in Computing Higher Education
}

\author{
Dawn Carmichael \\ Glasgow Caledonian University, Scotland, UK \\ Email: dawn.carmichael@gcu.ac.uk \\ Claire MacEachen \\ University of Abertay Dundee, Scotland, UK \\ Email: c.maceachen@ abertay.ac.uk
}

\begin{abstract}
The features of social media sites make them potentially effective as a learning platform for student communication and collaboration in higher education. Moreover it has become apparent that student Facebook users have been repurposing its features to fit their academic requirements. This study aims to determine if Facebook Groups and the Blackboard Learning Management System (LMS) can enhance the learner experience, and if so, in what way. The study made use of a heuristic evaluation with an educationally relevant criteria set [1]. The results, amongst other things, indicate that Facebook Groups are more useful for peer-to-peer communication than Blackboard, probably due to the notification system in Facebook. Analysis indicated that in some instances the strengths and weaknesses of Blackboard and Facebook were complementary and therefore could, arguably, improve the overall student experience.
\end{abstract}

Index Terms-Facebook, Learning Management Systems, E-Learning, Higher Education, Heuristics, Computing Education

\section{INTRODUCTION}

The pedagogic context for this paper is third year under-graduate BSc Computing students, studying Rich Internet Application (RIA) design and development. The students on the module have access to lecture notes and practical worksheets via Blackboard and, prior to this study, a discussion forum on Blackboard which was left unused. However it was noted that the BSc Computing students did make use of a course based Facebook group which was popular and contained regular postings and views.

The module material included examining RIA User Interface (UI) patterns and determining their fitness for particular requirements. Some UI patterns are a fairly abstract, for example 'progressive disclosure' [2] which involves only disclosing information to a user as it is required for an action. Progressive disclosure can be used in the design of input forms where settings' buttons can be optionally used; the pattern is also used in social media where there is a long list of replies that are truncated to the most recent with a link to expand other replies. Students are encouraged to discuss UI design patterns, but there are many to choose from and the key skill is to apply them in an appropriate way. It was decided that it could be useful for the module to create a Facebook group to be used in conjunction with Blackboard.

\section{EdUCATIONAL USE OF FACEBOOK}

Facebook has become a pervasive force in the daily lives of today's students [3], with more than 1 billion monthly users [4], half of which log on in any given day. This amounts to 700 billion minutes per month spent on Facebook [5]. Due to Facebook's popularity as a means of communication it has garnered a considerable amount of attention from academic institutions over the last decade [6], [7].

At present, educational institutions all over the world use Learning Management System (LMS) applications to manage and administer the education of their students [8]. Amoung the many functions that LMSs provide is the ability to engage in online communication via chat tools or discussion boards, as well as presenting course materials such as the ubiquitous PowerPoint presentation. There are competing views regarding the efficacy of using Facebook in Higher Education which are exemplified by; Kirschner \& Karpinski [9] who assert that Facebook is a waste of student time leading to lower grades whilst on the other hand Junco et al [10] states that posting to Facebook is positively correlated with engagement. Whilst these findings are not mutually exclusive they do suggest that there is a lack of a clear understanding about how to evaluate social media for an andragogical setting. Therefore the first step will be to examine student view on the roles of LMS and Facebook. 


\section{A. Student Views on Facebook and LMS}

Ellison [11] reported that over $85 \%$ of students she surveyed were using one or more social media service [11]. She also stated that virtually all of the students surveyed used social media to stay in touch with friends, two thirds to share photos etc. and approximately half as a way of inviting friends to events. Interestingly, almost half of the students surveyed had integrated social media into their academic life. The main method of integration reported was for communication with fellow students about course related topics. Despite this potential it is worth noting that only $5.5 \%$ of students indicated that their academic use of social media extended to communication with academic staff [11]. Along similar lines Selwyn [12] explored the use of Facebook by his students, finding that educationally related material accounted for a relatively small fraction of the total number of posts in his study. When students did use Facebook for academic purposes, it was usually aimed at practical information such as finding out when and where lectures were being held, assessment delivery information and coping with other demands of one's degree course [12]. Khan and Bakhsh [13] also found value in the use of Facebook for collaboration and discussion, but warned of the challenge of keeping discussion on topic. On the other hand student perception of LMSs is as an information resource only. They are viewed as places where they can retrieve course material or assessment details, rather than as resources which could be used to communicate with classmates [14]. Taken as a whole, findings suggest that Facebook is already used for student to student communication, in a general and non-tutor structured way, whilst the use of LMS has been well established for over a decade as a repository of information and course resources. However the coopting of Facebook into Higher Education has a number of issues arguably chief amongst them is user privacy.

\section{B. Privacy Issues with the academic use of Facebook}

Some academics have reported that they are "learning more about the students they teach simply by viewing the student's profile" [15]. Therefore it is perhaps unsurprising that a recurring concern for students is the ability for lecturers or other faculty to view their profiles. They fear that disclosure of their profile may have a negative effect on the tutor's impression of them. Jones et al [16] carried out a study at four separate universities to explore student perception of using social media to aid their studies. They found that students preferred to keep their social life separate from their academic life. Jones et al put forward a notion that in order to combine social media with education, there is a need to find the appropriate demarcation [16]. In a similar vein; Cloete, de Villiers \& Roodt [17] reported that students had concerns about "the amount of personal information displayed on the site.”. Furthermore, Maranto \& Barton [18] stated that students have complained about 'privacy violations' by faculty. From the perspective of teachers in Higher Education, Ellison [19] suggested that there is a potential for any lecturers to harm their image, and that Facebook use could lead to an unwanted reshaping of the lecturer-student relationship as well as the fact that the content is unaccountable to educational institutions [20].

Given the privacy concerns about using Facebook in an academic context in this study the Facebook Group facility was used. Facebook groups are discussion fora that can be set up for specific user groups and can be set to private. The Facebook Group content is therefore quite separate from the postings and profile information. The Facebook group was therefore used to allow the lecturer and students to post information and comment but removed the privacy issues reported in other studies.

\section{Key Findings on the Academic use of Facebook}

In her study of undergraduate students Ellison [19] found that Facebook was already integrated into students daily practices, it could be used for academic purposes to create a higher level of student engagement, and it added a 'social' peer-to-peer component. Furthermore it has been suggested that Facebook can help to foster social communication between students and with staff [21]. Another study found that the benefits included; increased interactive capabilities, improved student reflection and opportunities for self-presentation and personalisation [15]. The paper by Griffith \& Liyanage [15] suggested that students had a good perception of Facebook and that it was more popular than traditional offerings. Furthermore in a more recent study into the educational use of Facebook groups it was found that students who chose to ignore the Facebook postings reported lower engagement with the module content [22].

The literature also contains several other instances of the use of a Facebook group as an educational tool. For instance a study was carried out by Fontana [23], at Bowling Green State University in Ohio. The original intention was to use a Facebook Group as a vehicle for course updates and announcements. It was found that students were using it to ask course related questions and to collaborate with fellow students, posting images of their artwork allowing others to provide feedback. Additional findings were as follows; students made more of an effort to check the Facebook Group compared to the university's system; students felt less embarrassed about asking course related questions on Facebook compared to in class; and students were more comfortable using Facebook, due to previous familiarity, rather than the university's system [23].

A study by Bicen and Cavus [24] suggested that Facebook provides individuals with a way of maintaining and strengthening social ties, which can be beneficial in both social and academic settings. Similarly in another study it was suggested that the inclusion of Facebook in higher education not only helps students build social connections but can also facilitate self-expression [25].

In summary the literature yields several key areas for investigation that will be used to analyse students' explanations in the heuristic evaluation:

\section{Student daily [or regular] practices - [20]}


2. Peer-to-peer, social interactions - [20] [24] [25] [21]

3. Self-presentation and personalisation - [15] [25]

4. Posting work.......Feedback - [23]

5. Facebook [popular] as opposed to traditional resources - [15] [23]

\section{Methodology}

The aim of this study was to examine the use of Facebook groups and a Learning Management System (in this case Blackboard) to identify student perception of their efficacy for learning. In particular, the researchers were interested in identifying whether the benefits of one tool would outweigh the shortfalls in another.

\section{A. Pedagogic Context}

The setting for this study was with forty-eight year three BSc Computing students (from a four-year programme), studying Rich Internet Application (RIA) design and development. Students could retrieve lecture notes and practical exercise from Blackboard. Additionally, a Facebook Group was used to allow students to post questions to the lecturer and communicate with other students. The Facebook Group could be accessed via a link on Blackboard or via the student's personal Facebook page, after subscription to the group. Approximately $94 \%$ of the student population elected to join the group. The group was private rather than public. Student volunteers $(n=27)$ completed a heuristic evaluation during the thirteenth week after twelve weeks of study.

\section{B. Method Rationale}

The use of surveys to obtain student feedback is a wellestablished practice at many universities and often the evaluation of blended learning initiatives is folded into such surveys. However surveys of this type cannot help us to examine particular facets of the learning experience, such as the effectiveness of peer-to-peer communication provision for a given module. Heuristic evaluation, on the other hand, is a method which involves experts judging whether a given technology adheres to specific principles [26] aimed at testing the overall usability of technology in an efficient manner. Heuristic evaluation was chosen in this study because it was concerned with BSc Computing students who were familiar with the process of the technique.

There is a considerable range of heuristic sets [26], [27] which can vary in detail and emphasis. However general usability heuristics don't encapsulate the user requirements of educational technology. E-learning systems have specialised components to enable the transmission of knowledge which have previously been evaluated using the Technology Acceptance Model (TAM) [28]. It has been argued, however, that the TAM model is not appropriate for evaluating interactive media [29]. Whale et al [1] have put forward a seven element heuristic set which is intended to encapsulate the requirements for e-learning technology and interactive media. Whale et al [1] used their heuristic set along with the TAM model in a phased approach. However in this case study the Whale et al [1] heuristics were used as the basis for a one phase evaluation.

One of the Whale et al [1] criteria was divided into two. The criterion "Learner Motivation, creativity and learning", has been split into 'Learner Motivation' and 'creativity and learning' after feedback from a pilot study indicating that taken together they were unclear. Therefore the Whale et al [1] heuristic set used in this study number eight (see appendix A). The heuristics were utilised using a seven point Likert scale, 1-7 low to high.

\section{Method Procedure}

All the volunteer evaluators convened in a class room. The heuristic evaluation was run by two student volunteers acting as facilitators (no lecturers were present) over a period of around twenty minutes. The facilitators introduced the evaluation explaining the process of recording the responses online. Each of the heuristics had a seven point Likert scale and a comment box which evaluators were asked to respond to by explaining the reasoning behind their heuristic score. Student evaluators were encouraged to discuss their judgement with each other and the facilitators.

The scores for each heuristic and both Blackboard and Facebook were averaged. The scores were then analysed use a paired t-test. A t-test is of limited value where the samples are not truly independent and not in a normal distribution. Despite this the t-test was used as a means of arriving at threshold difference between the two scores. The comments/explanations, for each heuristic, were analysed using the main points detailed in the summary of the literature (see above). Comments were counted as relevant if the phrases were a match, synonym or similar in meaning. Each student was counted only once, therefore the maximum score would be 27 indicating that all students mentioned the topic.

\section{RESULTS}

This section contains a description of the results obtained from a heuristic evaluation which involved 27 student evaluators scoring heuristics and providing explanations for the scoring. Students also provided a view on preference on using only Facebook, only Blackboard or Both resources.

Table 1.Heuristic Means for Blackboard \& Facebook

\begin{tabular}{|l|l|l|}
\hline Heuristic (adapted) & $\begin{array}{l}\text { Blackboard } \\
\text { Mean }\end{array}$ & $\begin{array}{l}\text { Facebook } \\
\text { Mean }\end{array}$ \\
\hline Relevance of content & 6.1 & 3.6 \\
\hline Learner control & 3.6 & 5.1 \\
\hline Personal significance & 3.4 & 5.2 \\
\hline Peer-to-peer communication & 1.4 & 6.2 \\
\hline Creative active learning & 5.0 & 3.6 \\
\hline Learner motivation & 4.6 & 4.7 \\
\hline Perceived usefulness & 5.8 & 3.8 \\
\hline Perceived ease of use & 5.1 & 4.6 \\
\hline
\end{tabular}


The results of averaging the 27 students' individual scores for each of the Whale et al [1] adapted criteria is shown in table 1 .

The results from table 1 are shown in the radar chart below in figure 1 . The heuristics were organised left and right to show the differences between Blackboard and Facebook more clearly.

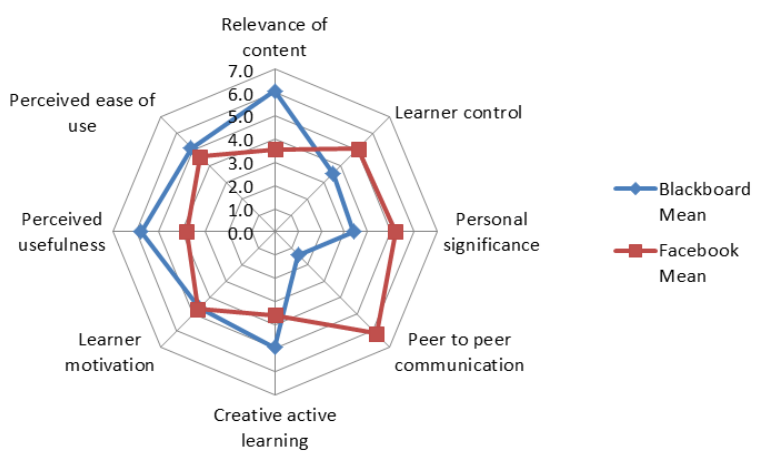

Fig.1. Heuristics Means Blackboard \& Facebook

Figure 2 shows that Blackboard scored more highly with criteria positioned on the left of the radar chart e.g. 'perceived usefulness' whilst Figure 3 shows that Facebook scored more highly with criteria positioned on the right such as 'learner control'.

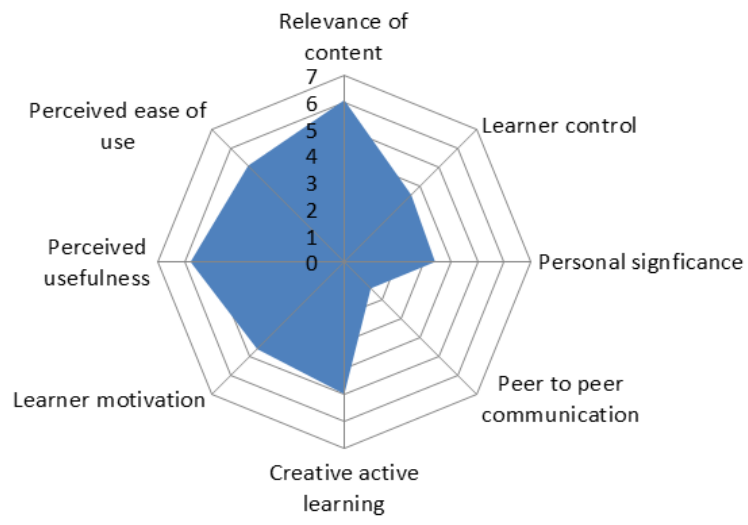

Fig.2. Blackboard Heuristic Means

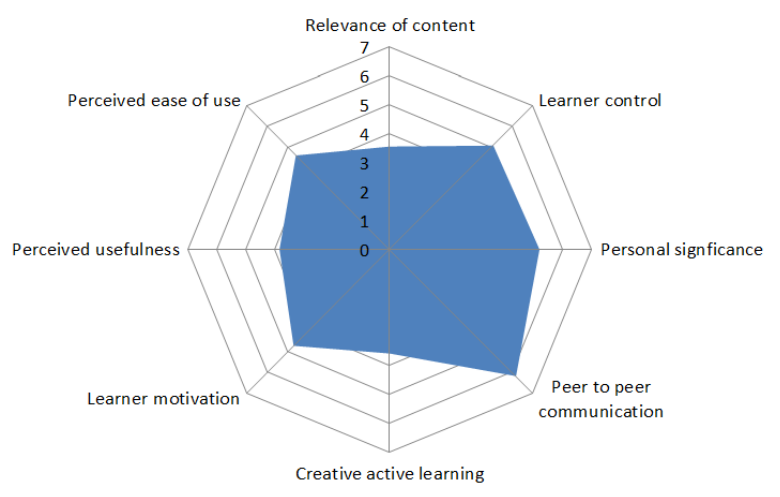

Fig.3. Facebook Heuristic Means
Figure 4 illustrates that taken together the results for both Blackboard and Facebook provide more consistent results for all of the criteria.

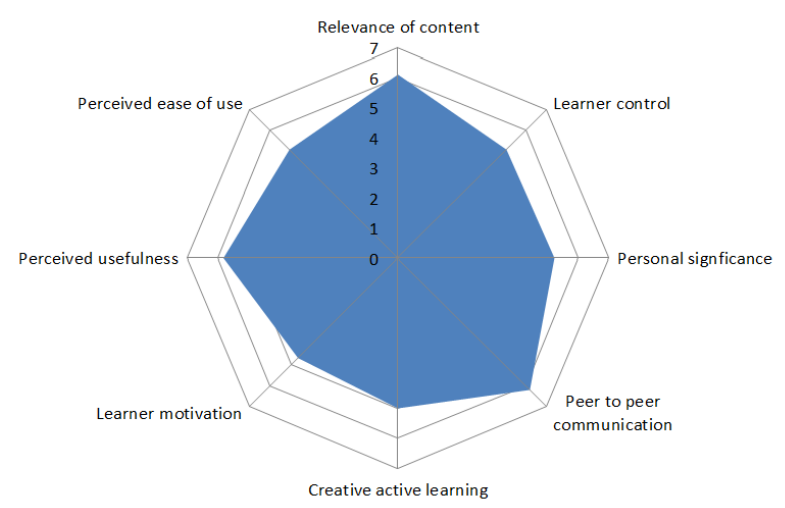

Fig.4. Heuristic Means, highest from either Blackboard or Facebook

The eight results for the two software systems were examined in pairs using a t-test in order to determine if there was a statistically significant difference between the two pairs of scores. This was done in order to determine if one software system was better for a given criteria than the other. For example; if there was a big difference between Facebook and Blackboard scores for the first heuristic it would be statistically significant, if they were close there would not be. The results of the t-tests are shown in table 2 .

Table 2. Heuristics Analysis

\begin{tabular}{|l|l|l|}
\hline $\begin{array}{l}\text { Heuristic from Whale } \\
\text { et al [1] }\end{array}$ & Higher Score & $\begin{array}{l}\text { Significant } \\
\text { P<.05 }\end{array}$ \\
\hline Relevance of content & Blackboard & Yes \\
\hline Learner control & Facebook & Yes \\
\hline Personal significance & Facebook & Yes \\
\hline $\begin{array}{l}\text { Peer-to-peer } \\
\text { communication }\end{array}$ & Facebook & Yes \\
\hline $\begin{array}{l}\text { Creativity and active } \\
\text { learning }\end{array}$ & - & No \\
\hline Learner motivation & - & No \\
\hline Perceived usefulness & Blackboard & Yes \\
\hline Perceived ease of use & - & No \\
\hline
\end{tabular}

In addition to the heuristics likert scores student evaluators were asked to explain their scores in comment boxes.

Table 3. Results of Analysis of Evaluator Comments

\begin{tabular}{|l|l|}
\hline Point & $\begin{array}{l}\text { Number } \\
\text { of Evaluator Mentions }\end{array}$ \\
\hline $\begin{array}{l}\text { Student daily [or regular] } \\
\text { practices - [20] }\end{array}$ & 8 \\
\hline $\begin{array}{l}\text { Peer-to-peer, social } \\
\text { interactions - [20] [24] [25] } \\
{[21]}\end{array}$ & 27 \\
\hline $\begin{array}{l}\text { Self-presentation and } \\
\text { personalisation - [15] [25] }\end{array}$ & 11 \\
\hline $\begin{array}{l}\text { Posting work.....Feedback - } \\
{[23]}\end{array}$ & 0 \\
\hline $\begin{array}{l}\text { Facebook [popular] as } \\
\text { opposed to traditional } \\
\text { methods - [15] [23] }\end{array}$ & 0 \\
\hline \multicolumn{2}{|c|}{. } \\
\hline
\end{tabular}


Table 3 shows the results of analysing the comment boxes using the key findings from the literature (shown on the left) as a framework. There were a total of 27 student evaluators to eight heuristics. Comments were counted as relevant if the phrases were a match, synonym or semantically similar; for example if the comment contained a mention of 'student daily practices' or similar it was counted as 1 . Each student was counted only once, therefore the maximum score would be 27 .

The student evaluators were also asked to score, on a five point scale from 'very low' to 'very high', the following three learning platform options:

- Facebook only

- Blackboard only

- Both

Each score was converted into percentages as given in table 4 illustrated in fig 5 .

Table 4. Overall Ratings for Platform Preference

\begin{tabular}{|l|c|c|c|}
\hline & Blackboard & Facebook & Both \\
\hline Very Low & $11 \%$ & $30 \%$ & $7 \%$ \\
\hline Low & $15 \%$ & $26 \%$ & $7 \%$ \\
\hline Neutral & $19 \%$ & $15 \%$ & $15 \%$ \\
\hline High & $26 \%$ & $19 \%$ & $30 \%$ \\
\hline Very High & $30 \%$ & $11 \%$ & $41 \%$ \\
\hline
\end{tabular}

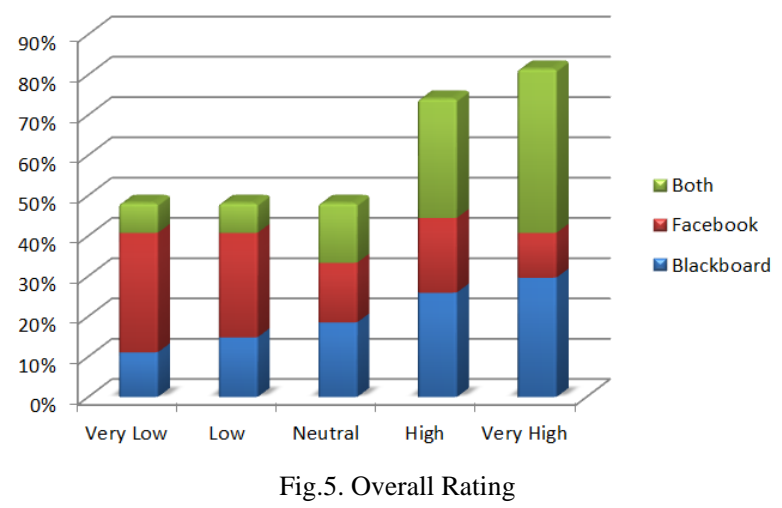

The data shows that the largest of proportion of "very high' ratings was given by student evaluators for 'both'. This result indicates that students who prefer to have both Facebook groups and Blackboard.

The results are discussed in the next section.

\section{DISCUSSION}

The results of averaging the scores from the heuristic evaluation, shown in figures 2 and 3, suggest that Blackboard and Facebook have strengths and weaknesses that may be complementary. Where Blackboard scored lowest was in supporting 'peer-to-peer communication' with 1.4 out of 7 . Facebook, on the other hand, had its highest score, of 6.2, for 'peer-to-peer communication'.
Furthermore in terms of Facebook its lowest score was 3.6 for both 'relevance of content' and 'creative active learning', whilst Blackboard scored 6.1 and 5.0 respectively. These complementary strengths and weakness are illustrated by examining figure 2 where the Blackboard radar chart is denser on the left and in figure 3 where the Facebook radar chart is denser on the right. The heuristics are organised to illustrate the differences more clearly. Figure 4 shows the radar chart for the combined scores, which presents a much more consistent pattern of scores for the heuristics and the potential educational strength of a combined tool approach.

The first two criteria concerning 'relevance of content' and 'learner control' had statistically significant difference in the scores (see table 1) with first Blackboard scoring higher and then Facebook. However, recall, that the t-test results are only indicative as the samples are not part of a normal distribution nor truly independent. It does, however, suggest that there is a meaningful difference between the two software systems, and that students accept Blackboard as a source of information but feel they have more control over Facebook. This result is not surprising, Blackboard is configured and administered by academics and therefore one would expect that it is an effective conduit for content and at the same time limits the ability of students to personalise their workspace. Facebook, on the other hand, is independent of academic institutions and 'owned' by the individual student. The result lends support for the suggestion that the two pieces of software can provide different benefits to the process of learning.

The third result, from table 2, was that students found that Facebook provided them with more 'personal significance' (in approaches to learning) than Blackboard and that the difference between the two scores (see table 1) was statistical significant. The literature suggests that Facebook provided opportunities for self-presentation and personalisation [15] as well as self-expression [25]. This study had a similar finding and overall lends support to the argument that Facebook can provide facilities for personal agency. Similarly the fourth result concerning 'peer-to-peer communication', again with statistically significant difference between the two scores, suggests that Facebook can add functionality that Blackboard does not provide. There are several sources in the literature stating that Facebook communication interactions are valued by students [20], [21], [24], [25]. It would appear that there is substantial support, in this study and others, for the idea of re-purposing Facebook for educational communication.

Results for heuristic five 'creativity and active learning' and six 'learner motivation' did not have a statistically significant difference between Facebook and Blackboard. Although the Blackboard results for heuristic five was higher than Facebook. This finding is interesting in terms of the literature. It was suggested that Facebook was useful to students for posting and critiquing art work [23]. In this study students preferred Blackboard to Facebook for creative and active learning. It is worth noting, however, that the students in this study were engaged in 
the development of software from a logical problem solving point of view rather than from a creative point of view. This difference in subject of study between the cohorts may account for the discrepancy in findings between the two studies.

The results for heuristic number six, 'perceived usefulness', showed a significantly higher score for Blackboard than Facebook. This result will no doubt have been influenced by the fact that the primary material for the module was made available via Blackboard whilst Facebook was used to provide a means of discussing that material. The final heuristic 'perceived ease of use' did not result in significantly different scores between Blackboard (5.1) and Facebook (4.6). The literature has suggested that students found Facebook ease to use [15], [23], this study does not contradict this as 4.6 is not a low score. However, students participating in this study were exposed to use of Blackboard in many modules prior to meeting it in this module and this familiarity may explain the variance from other studies.

The heuristic evaluation involved asking students to provide an explanation for their scoring. These comments were analysed for words and phrases linked to key terms taken from the literature. The findings, summarised in table 3, showed that student evaluators were aware of the social interactions afforded by Facebook and to a lesser extent on the software facilities for self-presentation. The most interesting result from this analysis was that 8 students commented that the Facebook was part of their daily practices and that the notifications system in Facebook drew them to checking the Facebook Group. These notifications are perhaps part of the reason that Facebook Groups were more popular than the Blackboard discussion forum had been in previous deliveries of the case study module.

The final result given in table 4 and fig 5 were taken from an overall ratings question. The student evaluators were asked to give a rating on whether they preferred only Blackboard, only Facebook or both. The ratings were expressed as a five point Likert scale. The results showed that the largest number of scores was in the 'Very High' category for 'both' platforms. It is unsurprising that students would prefer to have access to more technology rather than less, particularly given they are computing students. However the finding does provide a useful validation; given that the strengths and weaknesses of Blackboard and Facebook are complementary students actually do find using both to be an attractive proposition. However, even when students are lacking in computing and Facebook experience, such as in the study by AlMashaqbeh [30] the acceptance of such tools as support for learning is high.

The use of heuristic evaluation using educationally relevant criteria in the manner explained above has been useful. It has enabled an evaluation which shows the utility of features provided by the two software systems. The methodology which involves treating students as experts was simple and straight forward. As for the heuristics, concrete concepts such as 'relevance of content' and 'peer-to-peer communication' were easy to interpret. However other heuristics such as 'active learning' and 'learner motivation' are more complex and are less effective in eliciting clear responses. Further work on clarifying the heuristics would be useful.

\section{CONCLUSIONS}

In summary this case study has made use of heuristic evaluation using an educational technology based heuristic set [1] to compare Blackboard and Facebook. The results were analysed by looking for significant differences between the two software systems in order to determine where gaps in functionality might exist. It was found that that Blackboard and Facebook have complementary strengths and weaknesses for example; Blackboard was found to useful for 'relevance of content' and Facebook for 'peer-to-peer communication'. It was also noticed that Facebook scored highly for 'personally significant approaches to learning' whilst, Blackboard scored highly for 'relevant content' and 'perceived usefulness'. In previous experience it had been found that the Blackboard discussion forum was not used by students. An analysis of the evaluator explanations indicated that the Facebook notifications system may have drawn students attention to updates in the Facebook Group resulting in a greater usage. Overall this study supports previous findings in the literature regarding the usefulness of Facebook and suggests that both LMS and social media can together enhance the student experience.

\section{APPENDIX A AdAPTED HeURISTIC SET}

The heuristics are outlined below together with clarifying questions given in italics.

1. Relevance of content to the learner and the learning process

How closely related to your studies (subject matter and process of acquiring knowledge) was the content in the target resource?

2. Level of learner control

To what extent did you feel that you could make changes (to either personalise or contribute) to the target resource?

3. Support for personally significant approaches to learning

To what extent did you feel that you could organise the target resource in a way that suited your learning preferences?

4. Learner motivation

To what extent did you feel that the target resource (either the functionality or the content) increased your motivation to learn more about the topic?

5. Creativity 
To what extent did you feel that the target resource (either the functionality or the content) increased your creativity?

6. Active learning

To what extent did you feel that the target resource (either the functionality or the content) increased the amount of learning activities (posting, writing, problem solving, designing etc.) rather than reading?

7. Support for communication with peers

To what extent did you feel that the target resource supported communication with fellow students?

8. Perceived usefulness

Overall how would you rate the target resource (either the functionality or the content) in terms of its usefulness to you?

9. Perceive ease of use Overall how would you rate the target resource (either the functionality or the content) in terms of its ease of use?

\section{REFERENCES}

[1] B. M. Whale, A. P. Sholtz, and A. M. Calitz, "Classification of Heuristics for Components of eLearning," in Saicsit 2015, 2015, no. 43.

[2] J. Nielsen, "Progressive Disclosure," nngroup.com, 2006. [Online]. Available: https://www.nngroup.com/articles/progressive-disclosure/. [Accessed: 03-Apr-2017].

[3] R. E. Wilson, S. D. Gosling, and L. T. Graham, "A review of Facebook research in the social sciences.," Perspect. Psychol. Sci., vol. 7, 2012.

[4] D. Tam, "Facebook by the numbers: 1.06 billion monthly active users," 2013. [Online]. Available: http://news.cnet.com/8301-103_3-57566550-93/facebookby-the-numbers-1.06-billion-monthlyactive-users/.

[5] Facebook, "Press Room Statistics," Facebook, 2016. [Online]. Available: http://www.facebook.com/press/info.php?statistics.

[6] D. M. Boyd and N. B. Ellison, "Social Network Sites: Definition, History, and Scholarship," J. Comput. Commun., vol. 13, no. 1, Oct. 2007.

[7] D. Beer, "Social network(ing) sites...revisiting the story so far: A response to Danah Boyd \& Nicole Ellison," $J$. Comput. Commun., vol. 13, 2008.

[8] S. Lonn and S. D. Teasley, "Saving time or innovating practice: Investigating perceptions and uses of Learning Management Systems," Comput. Educ., vol. 53, 2009.

[9] P. A. Kirschner and A. C. Karpinski, "Facebook ${ }^{\circledR}$ and academic performance.," Comput. Human Behav., vol. 26, no. 6,2010

[10] R. Junco, "The relationship between frequency of Facebook use, participation in Facebook activities, and student engagement," Comput. Educ., vol. 58, no. 1, Jan. 2012.

[11] N. . Ellison, “'Social Networking Sites' Students and Information Technology," in ECAR Research Study 8, 2008.

[12] N. Selwyn, 'Screw Blackboard... do it on Facebook!' An investigation of students' educational use of Facebook," in Poke 1.0 - Facebook social research symposium, 2007.
[13] S. Khan and S. Tahir Bakhsh, "A Study on the Role of Facebook in E-Learning," Int. J. Educ. Manag. Eng., vol. 5, no. 5, pp. 1-11, Oct. 2015.

[14] G. Alsop and C. Tompsett, "Grounded Theory as an approach to studying students' uses of learning management systems," Assoc. Learn. Technol. Journa, vol. $10,2002$.

[15] S. Griffith and L. Liyanage, "An introduction to the potential of social networking sites in education," in Proceedings of the Emerging Technologies Conference, 2008.

[16] N. Jones, H. Blackey, K. Fitzgibbon, and E. Chew, "Get out of MySpace!," Comput. Educ., vol. 53, 2009.

[17] S. Cloete, C. de Villiers, and S. Roodt, "Facebook as an academic tool for ICT lecturers," in Proceedings of the 2009 Annual Conference of the Southern African Computer Lecturers' Association, 2009.

[18] M. Maranto, G. \& Barton, "Paradox and Promise: MySpace, Facebook, and the Sociopolotics of Social Networking in the Writing Classroom," vol. 27, 2010.

[19] N. B. Ellison, "Facebook Use on Campus: A Social Capital Perspective on Social Network Sites," in ECAR Symposium, 2007.

[20] N. Ellison, C. Steinfield, and C. Lampe, "The Benefits of Facebook 'Friends:' Social Capital and College Students' Use of Online Social Network Sites," J. Comput. Commun., vol. 12, no. 4, Jul. 2007.

[21] A. Schroeder, S. Minocha, and C. Schneider, "The strengths, weaknesses, opportunities and threats of using social software in higher and further education teaching and learning," J. Comput. Assist. Learn., vol. 26, no. 3, 2010.

[22] B. Dyson, K. Vickers, J. Turtle, S. Cowan, and A. Tassone, "Evaluating the use of Facebook to increase student engagement and understanding in lecture-based classes," High. Educ., vol. 69, no. 2, Feb. 2015.

[23] A. Fontana, "The Multichronic Classroom: Creating an Engaging Environment for All Students," J. Found. Art Theory Educ. - FATE Rev., vol. 30, 2010.

[24] H. Bicen and N. Cavus, "Social network sites usage habits of undergraduate students: Case study of Facebook," Procedia-Soc. Behav. Sci., vol. 28, 2011.

[25] R. Wang, P. Scown, C. Urquhart, and J. Hardman, "Tapping the educational potential of Facebook: Guidelines for use in higher education," Educ. Inf. Technol., vol. 19, no. 1, Mar. 2014.

[26] J. Nielsen, "Usability Inspection Methods," in CHI '95 Mosaic of Creativity, 1995.

[27] W. Queensbery, The five dimensions of usability. NJ: Mahwah, Lawrence Erlbaum Associates, 2003.

[28] S. Sternad and S. Bobek, "Impacts of TAM-based External Factors on ERP Acceptance," Procedia Technol., vol. 9, 2013.

[29] Á. Dunne, M. A. Lawlor, and J. Rowley, "Young people's use of online social networking sites - a uses and gratifications perspective," J. Res. Interact. Mark., vol. 4, no. $1,2010$.

[30] I. Fares Al-Mashaqbeh, "Facebook Applications to Promote Academic Engagement: Student \&quot; s Attitudes towards the Use of Facebook as a Learning Tool," I.J. Mod. Educ. Comput. Sci. Mod. Educ. Comput. Sci., vol. 11, no. 11, pp. 60-66, 2015. 


\section{Authors' Profiles}

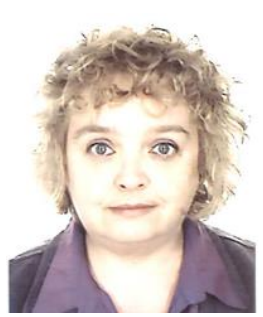

Dawn Carmichael has a $\mathrm{PhD}$ in the area of software metrics for social media. She currently holds a lectureship at Glasgow Caledonian University where she teaches HCI as well as web design and development. She is a fellow of the Higher Education Academy with pedagogic interests in the design of effective digital learning spaces. Her research interests include; social media analysis, software engineering, and UX design.

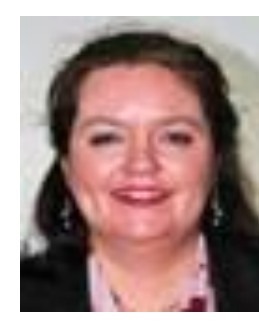

Claire MacEachen has been in academic management for almost 20 years as a head of an Information Systems department within a Computing School and then moving into a teaching/learning, quality assurance/enhancement role within the Dundee Business School (Abertay University). After originally starting her academic career in Computing (Business Information Systems) over 20 years ago, Claire transferred to more management based subjects 13 years ago. Her research interests have therefore merged the two areas of computing and teaching and learning.

How to cite this paper: Dawn Carmichael, Claire MacEachen,"Heuristic Evaluation of the use of Blackboard \& Facebook Groups in Computing Higher Education", International Journal of Modern Education and Computer Science(IJMECS), Vol.9, No.6, pp.1-8, 2017.DOI: 10.5815/ijmecs.2017.06.01 